\title{
Ulcerative colitis has an aggressive course after orthotopic liver transplantation for primary sclerosing cholangitis
}

\author{
G V Papatheodoridis, M Hamilton, P K Mistry, B Davidson, K Rolles, A K Burroughs
}

\begin{abstract}
Background-The course of inflammatory bowel disease after liver transplantation has been reported as variable with usually no change or improvement, but there may be an increased risk of early colorectal neoplasms. In many centres steroids are often withdrawn early after transplantation and this may affect inflammatory bowel disease activity.

Aims-To evaluate the course of inflammatory bowel disease in primary sclerosing cholangitis transplant patients who were treated without long term steroids. Methods-Between 1989 and 1996, there were 30 patients transplanted for primary sclerosing cholangitis who survived more than 12 months. Ulcerative colitis was diagnosed in $18(60 \%)$ patients before transplantation; two had previous colectomy. All patients underwent colonoscopy before and after transplantation and were followed for 38 (12-92) months. All received cyclosporin or tacrolimus with or without azathioprine as maintenance immunosuppression.
\end{abstract}

Results-Ulcerative colitis course after transplantation compared with that up to five years before transplantation was the same in eight $(50 \%)$ and worse in eight $(50 \%)$ patients. It remained quiescent in eight and worsened in four of the 12 patients with pretransplant quiescent course, whereas it worsened in all four patients with pretransplant active course $(p=0.08)$. New onset ulcerative colitis developed in three $(25 \%)$ of the 12 patients without inflammatory bowel disease before transplantation. No colorectal cancer has been diagnosed to date.

Conclusions-Preexisting ulcerative colitis often has an aggressive course, while de novo ulcerative colitis may develop in patients transplanted for primary sclerosing cholangitis and treated without long term steroids.

(Gut 1998;43:639-644)

Keywords: liver transplantation; inflammatory bowel disease; ulcerative colitis; primary sclerosing cholangitis; immunosuppression

Primary sclerosing cholangitis (PSC) is associated with inflammatory bowel disease (IBD) and most commonly with ulcerative colitis in $55-75 \%$ of patients. ${ }^{12}$ Although extent, duration, or severity of IBD correlates poorly with the natural course of PSC, ${ }^{1-5}$ patients with PSC usually have mild or asymptomatic but extensive colitis. ${ }^{367}$ As no specific treatment has been identified that can arrest the progression of liver disease in patients with PSC, hepatic failure and complications of portal hypertension develop in many cases, ${ }^{3}$ and then orthotopic liver transplantation (OLT) is the only potentially curable therapy. ${ }^{89}$

Immunosuppressive agents such as cyclosporin, steroids, and azathioprine, which are used after OLT, are considered as therapeutic options for IBD. ${ }^{10}{ }^{11}$ Hence, it would be anticipated that the course of IBD should improve after OLT or at least remain mild or asymptomatic as it had been before OLT. However, data from the few published studies of post-transplant IBD seem to be conflicting, as they describe a variable IBD course with mostly improving and rarely worsening disease. ${ }^{12-19}$ Furthermore, although the influence of OLT and the subsequent immunosuppression on cancer risk has not been clarified, there have been reports of an increased risk of early colorectal cancer in transplanted patients with IBD. ${ }^{17}{ }^{20-22}$ In many centres steroids are often withdrawn early post-OLT ${ }^{23} 24$ and this may affect the course of IBD. Therefore, we evaluated prospectively the course of IBD in patients transplanted for PSC who were treated without long term steroids as part of their maintenance immunosuppressive regimen.

\section{Methods}

\section{TOTAL POPULATION}

Between May 1989 and October 1996, a total of 41 patients with end stage liver disease due to PSC underwent OLT in our centre. There were 26 men and 15 women, with a mean age of 40 (13) years (range 17-63). The diagnosis of PSC was confirmed by pretransplant cholangiography and histological examination of the explant in all cases. The median duration of PSC from diagnosis was 50 (3-360) months and the mean bilirubin serum concentration was 192 (139) $\mu \mathrm{mol} / 1$ (range 44-604). Cholangiocarcinoma was present in four patients; it was detected before transplantation in two (as positive bile cytology without mass lesion), and found incidentally at explant in the other two patients (table 1).

Total colonoscopy was performed and colonic mucosa biopsy specimens were taken from all patients with PSC in the previous six months before OLT irrespective of bowel symptoms and previous IBD diagnosis. IBD diagnosis was based on clinical symptoms, 
Table 1 Characteristics of patients who underwent orthotopic liver transplantation for primary sclerosing cholangitis (PSC)

\begin{tabular}{ll}
\hline $\begin{array}{l}\text { No of patients } \\
\text { Male/female }\end{array}$ & 41 \\
Mean (SD, range) age (years) & $26 / 15$ \\
$\begin{array}{l}\text { Median (range) duration of PSC } \\
\text { (months) }\end{array}$ & $40(13,17-63)$ \\
Child class, n (\%) & $50(3-360)$ \\
$\quad$ B & $27(66)$ \\
C & $14(34)$ \\
Mean (SD, range) bilirubin ( $\mu$ mol/1) & $192(139,44-604)$ \\
Cholangiocarcinoma, $(\%)$ & $4(10)$ \\
$\quad$ Before transplantation & $2(5)$ \\
At explant & $2(5)$ \\
Patients with UC, n (\%) & $26(63)$ \\
Median (range) duration of UC & $86(2-480)$ \\
$\quad$ (months) & \\
Pretransplant UC course, n (\% UC & \\
$\quad$ patients) & $15(58)$ \\
Quiescent & $8(31)$ \\
Active & 0 \\
Steroid dependence & $3(11)$ \\
Colectomy &
\end{tabular}

UC, ulcerative colitis.

endoscopic findings, compatible colon histology, and exclusion of other causes of inflammation in all cases. All patients with IBD were evaluated in detail and characteristics of IBD course were carefully recorded. Characteristics of IBD included type, extent, and duration of IBD, maintenance treatment, number and severity of exacerbations, number of hospital admissions, courses and total duration of steroid therapy, need and duration of azathioprine therapy, and possible colectomy.

IBD was diagnosed in $26(63 \%)$ patients before OLT; 25 patients had total and one distal ulcerative colitis. Diagnosis of ulcerative colitis was made by routine pretransplant colonoscopy and histology in three asymptomatic patients and during exacerbation of disease at least 15 months before OLT in 23 patients. The median duration of ulcerative colitis was $86(2-480)$ months at time of OLT (table 1). The course of ulcerative colitis during the period up to five years before OLT was formally assessed pretransplant together with review of the medical records and it was considered quiescent if none or only one mild to moderate exacerbation of colitis had developed, steroid treatment had been given for less than two months, and there had been no need for hospital admission or no need for azathioprine treatment. Pretransplant ulcerative colitis course during the same period was considered active if there had been two or more mild to moderate exacerbations or one or more severe exacerbations of colitis or at least one hospital admission or treatment with steroids for more than two months or treatment with azathioprine. Patients who continuously needed steroids for maintaining remission were considered separately as steroid dependent as were those who had needed colectomy. Truelove and Witts criteria were used for classification of severity of ulcerative colitis exacerbation. ${ }^{25}$

Three $(11.5 \%)$ of the 26 patients with ulcerative colitis had undergone total colectomy before OLT; two because of intractability (1.5 and seven years before OLT) and one because of high grade dysplasia (six years before OLT). PSC had been diagnosed before colectomy in the first two patients and developed one year after colectomy in the third. Pretransplant ulcerative colitis course in the period up to five years before OLT was quiescent in $15(65 \%)$ and active in eight $(35 \%)$ of the remaining 23 patients. None of the 23 patients was taking azathioprine or was steroid dependent before OLT (table 1). No patient had active ulcerative colitis or was taking steroids at the time of transplantation and no ulcerative colitis exacerbation was observed in the previous 12 months before OLT. Twenty one patients were taking mesalazine $(n=15)$ or sulphasalazine $(n=6)$, while five patients were taking no maintenance ulcerative colitis treatment (including the three patients with incidental ulcerative colitis diagnosis at pretransplant colonoscopy).

POPULATION AFTER OLT

Only the $30(73 \%)$ patients who survived more than 12 months were included for the study of IBD after OLT. There were 18 men and 12 women, with a mean age of 38 (13) years (range 17-62). Survival was not significantly different with and without IBD (18/26 (69\%) versus $12 / 15(80 \%), p=0.36)$ and was not related to ulcerative colitis course before OLT. Twelve $(80 \%)$ of the patients with quiescent and four $(50 \%)$ of those with active pretransplant ulcerative colitis course as well as two $(67 \%)$ of the patients with previous colectomy survived more than 12 months $(p=0.33)$. Median ulcerative colitis duration was 85 (2-480) months at time of OLT; seven of the 16 patients had ulcerative colitis for more than 10 years. Ten patients were non-smokers (seven with quiescent and three with active pretransplant ulcerative colitis course), five patients had stopped smoking 2-17 years before OLT (all of them within 3-12 months before ulcerative colitis diagnosis), and one patient with quiescent pretransplant ulcerative colitis was an occasional smoker.

Deaths in the first 12 months were related to sepsis in six patients (five in the first two months and one in the sixth month after initial OLT or two months after retransplantation), complications of graft dysfunction in two patients (both in the first month after OLT), severe rejection in one patient (five months after OLT), rupture of hepatic hematoma in one patient (two months after OLT), and disseminated cholangiocarcinoma in one patient (nine months after OLT). No ulcerative colitis exacerbation was observed in this subgroup of patients.

Post-transplant maintenance immunosuppression was cyclosporin (10 $\mathrm{mg} / \mathrm{kg} /$ day) or tacrolimus $(0.1 \mathrm{mg} / \mathrm{kg} / \mathrm{day})$, both in two divided daily doses with $(n=18)$ or without $(\mathrm{n}=12)$ azathioprine (1 $\mathrm{mg} / \mathrm{kg} /$ day $)$. Steroids were withdrawn within six months in all but one patient, who received prednisolone for 12 months because of previous repeated rejection episodes. All patients with known ulcerative colitis were given long term mesalazine in standard dosage (1.5-2 g/day) within the first three months after OLT.

All patients were routinely observed for the development of colonic symptoms. The mean 


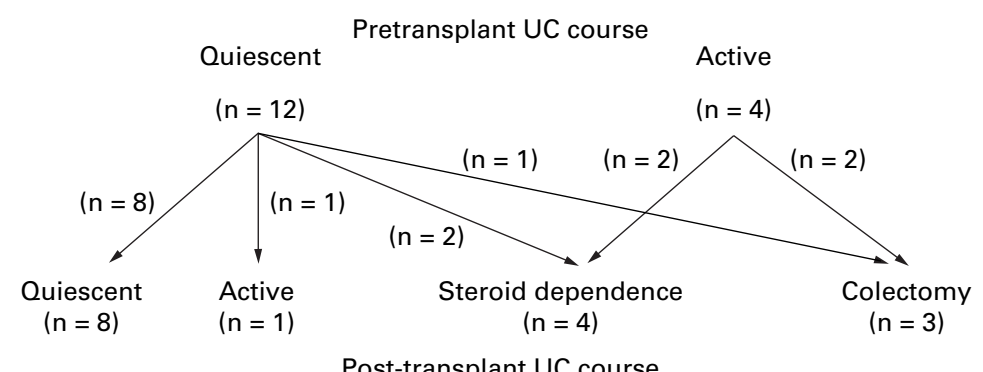

Post-transplant UC course

Figure 1 Relation between pre-and post-liver transplantation ulcerative colitis (UC) course.

follow up was 38 (21) months (range 12-92). Colonoscopy with colonic biopsies were performed at least once in all patients irrespective of bowel symptoms and IBD diagnosis. If symptoms of colitis developed, stool cultures for enteric pathogens and stool for ova, parasites, and Clostridium difficile toxins were checked, endoscopy was performed, and colonic biopsy specimens were examined for presence of cytomegalovirus (intranuclear inclusion bodies and immunohistochemical staining). Exacerbation of ulcerative colitis was diagnosed in cases with compatible colon histology and exclusion of other possible causes of colitis.

The course of ulcerative colitis during the total follow up period after OLT was compared with that in the period up to five years before OLT in the patients with previous established ulcerative colitis who had not undergone colectomy. The mean follow up in this group was 39 (17) months (range 12-74). Posttransplant ulcerative colitis course during the total follow up period after OLT was also classified as quiescent, active, steroid dependent, and patients with colectomy according to the same criteria used for classification of pretransplant ulcerative colitis course.

\section{STATISTICAL ANALYSIS}

Statistical analysis was carried out by corrected $\chi^{2}$ test, two tailed Fisher's exact test, $t$ test, and Wilcoxon rank sum test, when appropriate. All data were analysed using the statistical package SPSS 6.0

\section{Results}

POST-TRANSPLANT ULCERATIVE COLITIS ACTIVITY Post-transplant ulcerative colitis course after OLT compared with that during the five years

Table 2 Predictive factors of ulcerative colitis (UC) course after orthotopic liver transplantion (OLT) for primary sclerosing colangitis (PSC) compared with the UC course during the period up to five years before transplantation

\begin{tabular}{llll}
\hline & \multicolumn{2}{l}{ UC activity after } & \multirow{2}{*}{ OLT } \\
\cline { 2 - 3 } Patient characteristics & Same-Quiescent & Worse-Active & p Value \\
\hline Sex (M/F) & $4 / 4$ & $7 / 1$ & 0.28 \\
Age (years) at OLT & $42(12)$ & $30(11)$ & 0.11 \\
Age (years) at UC diagnosis & $31(12)$ & $22(6)$ & 0.11 \\
Median (range) duration of UC (months) & $86(3-480)$ & $85(2-250)$ & 0.64 \\
Median (range) duration of PSC (months) & $47(12-360)$ & $60(3-164)$ & 0.94 \\
Pretransplant UC course (n) & 8 & 4 & 0.08 \\
$\quad$ Quiescent & 0 & 4 & \\
$\quad$ Active & 3 & 2 & 0.64 \\
Immunosuppression (n) & 5 & $6^{\star}$ & \\
$\quad$ Cyclosporin & $5 y c l o s p o r i{ }^{\star}+$ azathioprine & & \\
\hline
\end{tabular}

$\star$ One patient was on tacrolimus. before OLT was the same in eight $(50 \%)$ and worse in eight $(50 \%)$ of 16 patients. Ulcerative colitis activity worsened after OLT in four $(33.3 \%)$ of the 12 patients with quiescent and in all four $(100 \%)$ with active pretransplant ulcerative colitis course $(\mathrm{p}=0.08)$. In particular, ulcerative colitis after OLT remained quiescent in eight $(66.7 \%)$, became active in one $(8.3 \%)$, and steroid dependent in two $(16.7 \%)$, and ended with a colectomy in one $(8.3 \%)$ of the patients with a quiescent pretransplant ulcerative colitis course. It became steroid dependent in two (50\%) and ended with a colectomy in the other two $(50 \%)$ of the patients with an active pretransplant ulcerative colitis course (fig 1).

All ulcerative colitis exacerbations were observed after steroid withdrawal and at least four months after OLT. In total, three $(19 \%)$ of the patients underwent total colectomy at 9, 14, and 47 months after OLT. Indications for colectomy were severe acute exacerbations in the first two and intractable disease in the third patient.

Post-transplant ulcerative colitis activity was not found to be related to patients' sex, age at OLT, age at ulcerative colitis diagnosis, ulcerative colitis duration, PSC duration, or type of immunosuppression (cyclosporin alone or in combination with azathioprine) (table 2). With regard to smoking habits, post-transplant ulcerative colitis activity was worse in six of the 10 non-smoking patients and in two of the five patients who had stopped smoking before OLT.

Post-transplant ulcerative colitis course was not associated with graft survival. Patients with quiescent or active ulcerative colitis course after OLT had a similar incidence of acute $(80 \%$ and $100 \%$ respectively, $\mathrm{p}=0.23)$ or chronic rejection ( $25 \%$ versus $14 \%, \mathrm{p}=1.00$ ) and of retransplantation $(12.5 \%$ versus $37.5 \%$, $\mathrm{p}=0.32$ ) and similar duration of steroid treatment for cellular rejection (3.1 months in both groups).

DE NOVO IBD

Typical clinical and biopsy proved IBD developed in three $(25 \%)$ of the 12 patients without IBD before transplantation who survived at least 12 months. Total ulcerative colitis was diagnosed in all cases at 9, 32 (or 11 months after retransplantation because of chronic rejection), and 45 months after OLT. Pretransplant colonoscopy and colon histology were completely normal in the two patients diagnosed at 32 and 45 months (both on cyclosporin and azathioprine). In the other patient, pretransplant check colonoscopy (two weeks before OLT) had showed mild oedema of the mucosa and colonic histology had revealed patchy mild non-specific inflammation; there was no history of diarrhoea or other symptoms or signs suggestive of IBD. Steroids had been withdrawn in the sixth month after OLT; she had been on monotherapy with cyclosporin.

De novo ulcerative colitis developed in three $(60 \%)$ of five female and in none of seven male patients $(p=0.04)$. Age at OLT, duration of 
Table 3 Course of inflammatory bowel disease (IBD) after orthotopic liver transplantation (OLT) compared with the IBD course before OLT in published studies

\begin{tabular}{|c|c|c|c|c|c|c|c|c|c|}
\hline \multirow[b]{2}{*}{ Reference } & \multirow[b]{2}{*}{$\begin{array}{l}\text { Maintenance } \\
\text { immunosuppression }\end{array}$} & \multirow{2}{*}{$\begin{array}{l}\text { Follow } \\
\text { up after OLT } \\
\text { (months) }\end{array}$} & \multirow[b]{2}{*}{$\begin{array}{l}\text { Pre-OLT IBD } \\
\text { activity }\end{array}$} & \multirow[b]{2}{*}{$\begin{array}{l}\text { No of } \\
\text { patients }\end{array}$} & \multirow[b]{2}{*}{$\begin{array}{l}\operatorname{Sex} \\
(M / F)\end{array}$} & \multirow[b]{2}{*}{$\begin{array}{l}\text { Age } \\
\text { (years) }\end{array}$} & \multicolumn{3}{|c|}{$I B D$ course after $O L T$} \\
\hline & & & & & & & $\begin{array}{l}\text { Same } \\
(n(\%))\end{array}$ & $\begin{array}{l}\text { Better } \\
(n(\%))\end{array}$ & $\begin{array}{l}\text { Worse } \\
(n(\%))\end{array}$ \\
\hline Gavaler et al ${ }^{12}$ & Cyclosporin+prednisolone & $\begin{array}{l}\text { NA } \\
110 \\
83\end{array}$ & $\begin{array}{l}\text { Total } \\
\text { Quiescent } \\
\text { Active }\end{array}$ & $\begin{array}{l}23 \\
6 \\
17\end{array}$ & $\begin{array}{l}15 / 8 \\
4 / 2 \\
11 / 6\end{array}$ & $\begin{array}{l}\text { NA } \\
35 \\
40\end{array}$ & $\begin{array}{l}9(39) \\
6(100) \\
3(18)\end{array}$ & $\begin{array}{l}14(61) \\
0 \\
14(82)\end{array}$ & $\begin{array}{l}0 \\
0 \\
0\end{array}$ \\
\hline Shaked et al ${ }^{13}$ & $\begin{array}{l}\text { Cyclosporin or } \\
\text { tacrolimus +azathioprine+ } \\
\text { prednisolone }\end{array}$ & $\begin{array}{l}30 \\
\mathrm{NA} \\
\mathrm{NA}\end{array}$ & $\begin{array}{l}\text { Total } \\
\text { Quiescent } \\
\text { Active }\end{array}$ & $\begin{array}{l}24 \\
13 \\
11\end{array}$ & $\begin{array}{l}\text { NA } \\
\text { NA } \\
\text { NA }\end{array}$ & $\begin{array}{l}\text { NA } \\
\text { NA } \\
\text { NA }\end{array}$ & $\begin{array}{l}12(50) \\
9(69) \\
3(28)\end{array}$ & $\begin{array}{l}4(17) \\
0 \\
4(36)\end{array}$ & $\begin{array}{l}8(33) \\
4(31) \\
4(36)\end{array}$ \\
\hline Stephens et al ${ }^{15}$ & $\begin{array}{l}\text { Cyclosporin or } \\
\text { tacrolimus+prednisolone+ } \\
\text { azathioprine }\end{array}$ & NA & Total & 27 & NA & NA & $4(15)$ & $18(67)$ & $5(18)$ \\
\hline Befeler et $a l^{26}$ & $\begin{array}{l}\text { Cyclosporin or } \\
\text { tacrolimus+azathioprine+ } \\
\text { prednisolone }\end{array}$ & $\begin{array}{l}37 \\
\text { NA } \\
\text { NA }\end{array}$ & $\begin{array}{l}\text { Total } \\
\text { Quiescent } \\
\text { Active }\end{array}$ & $\begin{array}{l}23 \\
6 \\
17\end{array}$ & $\begin{array}{l}\text { NA } \\
\text { NA } \\
\text { NA }\end{array}$ & $\begin{array}{l}\text { NA } \\
\text { NA } \\
\text { NA }\end{array}$ & $\begin{array}{l}12(52) \\
6(100) \\
6(35)\end{array}$ & $\begin{array}{l}11(48) \\
0 \\
11(65)\end{array}$ & $\begin{array}{l}0 \\
0 \\
0\end{array}$ \\
\hline This study & $\begin{array}{l}\text { Cyclosporin or } \\
\text { tacrolimus } \pm \text { azathioprine }\end{array}$ & $\begin{array}{l}39 \\
36 \\
48\end{array}$ & $\begin{array}{l}\text { Total } \\
\text { Quiescent } \\
\text { Active }\end{array}$ & $\begin{array}{l}16 \\
12 \\
4\end{array}$ & $\begin{array}{l}11 / 5 \\
8 / 4 \\
3 / 1\end{array}$ & $\begin{array}{l}36 \\
35 \\
39\end{array}$ & $\begin{array}{l}8(50) \\
8(67) \\
0\end{array}$ & $\begin{array}{l}0 \\
0 \\
0\end{array}$ & $\begin{array}{l}8(50) \\
4(33) \\
4(100)\end{array}$ \\
\hline
\end{tabular}

^Azathioprine or cyclophosphamide.

PSC, and type of immunosuppression did not differ between patients with de novo and those without IBD. Two patients were non-smokers and one had stopped smoking 2.5 years before OLT.

The course of ulcerative colitis was quiescent (only one mild or moderate exacerbation at presentation which responded immediately to a short course of steroids) in the two patients diagnosed at nine and 45 months and followed up for six and 48 months after ulcerative colitis onset. The disease had an active course in the third patient ending in steroid dependence eight months after the first presentation.

RISK OF NEOPLASIA

No colorectal neoplasm has been diagnosed to date. A renal tumour (hypernephroma) was treated with nephrectomy at transplantation.

Three patients with cholangiocarcinoma died of cancer recurrence. The two with carcinoma detected before OLT died at nine and 24 months after OLT and one of the two with carcinoma detected incidentally at explant died after 76 months. The fourth patient is alive and cancer-free 14 months after OLT.

\section{Discussion}

In our centre, post-transplant ulcerative colitis seems to run the worst reported course. In this group of patients in which steroids were withdrawn early after OLT, post-transplant ulcerative colitis activity improved in none and worsened in $50 \%$ of the patients. All patients with a worse ulcerative colitis course had more frequent and more severe exacerbations requiring steroids for their treatment; four of the eight became steroid dependent and another three had to undergo total colectomy.

The course of IBD in PSC transplanted patients is very variable as shown by data from published studies (see table 3). Furthermore, assessment of IBD activity differs between various studies and this makes comparisons even more difficult. The most favourable IBD course was described in three studies using steroids in maintenance immunosuppression regimens, where improvement of IBD after OLT was observed in $59 \%$ of patients (43/73), while only $7 \%(5 / 73)$ became worse. ${ }^{12} 1526$ Post-transplant IBD course was described as generally mild in three other reports but without any comparison to the pretransplant course of the disease..$^{141619}$ In another study, however, only $17 \%$ of patients (4/24) improved and 33\% became worse despite similar immunosuppression regimens. ${ }^{13}$ It should be noted that aggressiveness of IBD after OLT may have been overestimated in the latter series, as posttransplant course was compared with the immediate preoperative status of bowel disease and not to the activity of IBD over a longer period before OLT. ${ }^{13}$ Progressive IBD after OLT was described in $31 \%$ of patients $(6 / 19)$ in another recent study using triple immunosuppression, but four of the six patients reported to worsen had dysplasia or colon cancer and only two $(10.5 \%)$ patients actually had worse IBD activity. ${ }^{17}$ Liver transplantation does not seem to alter the course of pouchitis in patients with PSC with ileal pouch-anal anastomosis, although pathogenesis of pouchitis may be different from that of IBD and only a small number of patients have been reported. ${ }^{27}$ In a study from the Birmingham group, the only other study in which early steroid withdrawal was also used, poor control of IBD was observed in 35\% of patients (9/26) transplanted for PSC although no comparison to the pretransplant IBD activity was given. ${ }^{18}$

Summarising the above data, it seems that steroids or stronger immunosuppression may be very often needed as long term treatment for maintenance of remission in transplanted patients with IBD. In our study, all ulcerative colitis exacerbations presented after steroid withdrawal. Steroids, however, may not induce complete remission of bowel inflammation but may only control the patient's symptoms. In two studies where prednisolone was part of the maintenance immunosuppression regimen, evidence of active inflammation was often 
found endoscopically and histologically even in patients with clinically asymptomatic disease. $^{12} 13$

To date there is no hypothesis to explain or predict the post-transplant IBD course and its relation to immunosuppression. Patients with advanced liver disease often have a disturbed immune system and particularly depression of $\mathrm{T}$ cell function. ${ }^{28}{ }^{29} \mathrm{OLT}$ creates a new balance in immunoregulation: the new liver and the restoration of a competent immune system on one side, and the immunosuppressive drugs on the other. Inappropriate drugs or inadequate dosage may be responsible for IBD cases presenting with aggressive disease after OLT despite immunosuppression. Cyclosporin or tacrolimus either on their own or together with steroids and/or azathioprine are the most common immunosuppressive drugs used as maintenance treatment after OLT. Cyclosporin in the low oral doses usually used after the first few months in transplanted patients has been mainly tried in patients with Crohn's disease and found to be ineffective in maintaining remission. ${ }^{11}{ }^{30-32}$ The role of tacrolimus has not been clarified, although it has been reported that it may favourably influence the symptoms of post-transplant IBD. ${ }^{14}$ The dose of azathioprine may be important for prevention of IBD relapses, as dosage in transplanted patients is usually lower than the usual effective dose in IBD (1.0-1.5 versus $2.0-2.5 \mathrm{mg} / \mathrm{kg} /$ day). ${ }^{10}$ Steroids induce non-selective immunosuppression and are considered the treatment of choice for acute exacerbations of IBD. ${ }^{10}{ }^{33}$ Although steroids have not been shown to be effective for overall maintenance of remission in IBD, there is a group of patients which is unable to stay in remission while being weaned off the drug. ${ }^{10}$

Predictive factors for post-transplant ulcerative colitis course were not identified in our study. It is noteworthy, however, that ulcerative colitis had a worse course in all patients with an active pretransplant ulcerative colitis course and in only one third of patients with a quiescent pretransplant ulcerative colitis course $(\mathrm{p}=0.08)$; the relatively small number of patients might be responsible for the nonsignificance of this finding. Furthermore, it should also be noted that none of our patients with active pretransplant ulcerative colitis had active disease or was taking steroids at the time of transplantation.

To date de novo ulcerative colitis after OLT has developed in three of 12 patients and this was more common in female patients. New onset IBD cases after transplantation and in particular after liver transplantation have also been reported by others. ${ }^{134}$ Thus, it seems that an even closer association between PSC and IBD might exist if patients with PSC live long enough to express the colonic disease. The last observation favours the hypothesis of a common pathogenetic mechanism for both PSC and IBD, like autoimmunity against similar antigens in different target organs. ${ }^{35-37}$ It seems that even new onset IBD may have an aggressive course after OLT. Two of 14 patients with new onset IBD after renal or liver transplantation reported by Riley et al had to undergo colectomy ${ }^{34}$ and one of our three patients became steroid dependent in a relatively short period. Steroids may have an inhibitory role in presentation of new IBD cases after transplantation, as none of our patients or those reported Riley and coworkers $^{34}$ presented before discontinuation or before a significant decrease in steroid dose.

The longer life span of PSC and ulcerative colitis patients with OLT results in longer duration of colonic disease and subsequently increases the risk of colorectal cancer. ${ }^{38-40}$ Whether immunosuppressive drugs after OLT further increase the risk of colon cancer is not clear. No colorectal cancer developed in our patients nor in those reported by Shaked et $a l^{13}$ in a combined total of 40 patients followed up for 30-38 months after OLT. The low prevalence of colorectal cancer $(3 / 91$ or $3 \%)$ in transplanted patients with long standing ulcerative colitis was also described in a very recent report of a large number of patients. ${ }^{19}$ Contrary to the above mentioned studies, a high incidence $(5-14 \%)$ of colorectal cancer in such patients with a similar follow up has been reported by others. ${ }^{17}{ }^{20-22}$ However, seven of the eight cancer cases in the latter studies were detected in the first 9-27 months after OLT; all patients had extensive ulcerative colitis and duration of disease was more than 17 years in all but one patient (nine years). ${ }^{17}{ }^{20-22}$ The high detection rate of colorectal cancer in high risk patients with ulcerative colitis early after OLT favours the hypothesis of a preexisting malignant focus which may have an accelerated progression and become clinically detectable early on because of heavy immunosuppression or other conditions of transplantation.

In conclusion, ulcerative colitis, in patients transplanted for PSC and treated with early steroid withdrawal, seems to have an aggressive course in half of the cases despite maintenance immunosuppression with cyclosporin with or without low dose azathioprine; steroids are very often needed to treat the colonic disease. Whether steroids should be maintained long term remains a moot point, as there is a significant morbidity due to side effects. Perhaps the azathioprine dose could be increased, but the potential side effects, including possible oncogenesis, may be more likely and/or more severe in immunosuppressed patients. This needs more evaluation. De novo IBD, and particularly ulcerative colitis, may develop after OLT and this strengthens the association between PSC and ulcerative colitis. In contrast to other studies, the risk of colorectal cancer was not high in our patients despite similar follow up times. Careful study of the course of a preexisting or new onset immune mediated disease such as IBD in individuals on immunosuppressive drugs could help in our understanding of the pathogenesis of IBD and the ineffectiveness of maintenance immunosuppressive drug regimens in many such cases.

George V Papatheodoridis is in receipt of a scholarship from the Hellenic Association for the Study of Liver. 
1 Chapman RWG, Arborgh BAM, Rhodes JM, et al. Primary sclerosing cholangitis: a review of its clinical features, cholangiography, and hepatic histology. Gut 1980;21:8707 :

2 Wiesner RH, La Russo NF. Clinicopathologic features of the syndrome of primary sclerosing cholangitis. Gastroenterology 1980;79:200-6.

3 Balan V, LaRusso NF. Hepatobiliary disease in inflammatory bowel disease. Gastroenterol Clin North Am 1995;24: 647-69.

4 Shepherd HA, Selby WS, Chapman RWG, et al. Ulcerative colitis and persistent liver dysfunction. $Q \mathcal{F}$ Med 1983;52 503-13.

5 Schrumpf E, Elgjo K, Fausa O, et al. Sclerosing cholangitis in ulcerative colitis. Scand $\mathcal{F}$ Gastroenterol 1980;15:689-97.

6 Lundqvist K, Broome U. Differences in colonic disease activity in patients with ulcerative colitis with and without primary sclerosing cholangitis: a case control study. Dis Colon Rectum 1997;40:451-6.

7 Rabinovitz M, Gavaler JS, Schade RR, et al. Does primary sclerosing cholangitis occurring in association with inflammatory bowel disease differ from that occurring in the matory bowel disease differ from that occurring in the
absence of inflammatory bowel disease? A study of sixty-six absence of inflammatory bowel dise
subjects. Hepatology 1990;11:7-11.

8 Marsh JWJ, Iwatsuki S, Makowka L, et al. Orthotopic liver transplantation for primary sclerosing cholangitis. Ann Surg 1988;207:21-5.

9 Harrison J, McMaster P. The role of orthotopic liver transplantation in the management of sclerosing cholangitis. Hepatology 1994;20:14S-19S.

10 Hanauer SB. Inflammatory bowel disease. $N$ Engl f $\mathrm{Med}$ 1996;334:841-8.

11 Sandborn WJ. A review of immune modifier therapy for inflammatory bowel disease: azathioprine, 6-mercaptopurine, cyclosporine and methotrexate. Am 7 Gastroenterol 1996;91:423-33.

12 Gavaler JS, Delemos B, Belle SH, et al. Ulcerative colitis disease activity as subjectively assessed by patientdisease activity as subjectively assessed by patientcompleted questionnaires following orthotopic liver transplantation

13 Shaked A, Colonna JO, Goldstein L, et al. The interrelation between sclerosing cholangitis and ulcerative colitis in patients undergoing liver transplantation. Ann Surg 1992; 215:598-605

14 Kitis G, Wright HI, Abu-Elmagd K, et al. The course of inflammatory bowel disease under FK 506 immunosuppression after liver transplantation for primary sclerosing cholangitis [abstract]. Hepatology 1992;16(suppl):191A.

15 Stephens J, Goldstein R, Crippin J, et al. Effects of orthotopic liver transplantation and immunosuppression on inflammatory bowel disease in primary sclerosing cholangitis patients. Transplant Proc 1993;25:1122-3.

16 Fabry TL, Klion FM, Post JA, et al. Outcome of liver transplantation (OLTX) for primary sclerosing cholangitis
(PSC) and the effect of immunosuppression on the course of inflammatory bowel disease [abstract]. Hepatology 1993; 18(suppl):69A

17 Narumi S, Roberts JP, Emond JC, et al. Liver transplantation for sclerosing cholangitis. Hepatology 1995;22:451-7.

18 Miki C, Harrison JD, Gunson BK, et al. Inflammatory bowel disease in primary sclerosing choalngitis: an analysis of patients undergoing liver transplantation. $\mathrm{Br} \quad \mathcal{f}$ Surg 1995;82:1114-17.

19 Marotta PJ, Graziadei IW, Wiesner RH, et al. Inflammatory bowel disease in patients with primary sclerosing cholangitis receiving liver transplantation [abstract]. Hepatology 1997;26(suppl):237A

20 Higashi H, Yanaga K, Marsh JW, et al. Development of colon cancer after liver transplantation for primary scleros- ing cholangitis associated with ulcerative colitis. Hepatology 1990;11:477-80.

21 Bleday R, Lee E, Jessurum J, et al. Increased risk of early colorectal neoplasms after hepatic transplant in patients with inflammatory bowel disease. Dis Colon Rectum 1993;36:908-12.

22 Knechtle SJ, D'Alessandro AM, Harms BA, et al. Relationships between sclerosing cholangitis, inflammatory bowel disease, and cancer in patients undergoing liver transplantation. Surgery 1995;118:615-20.

23 Padbury RTA, Gunson BK, Dousset B, et al. Steroid withdrawal from long-term immunosuppression in liver allograft recipients. Transplantation 1993;55:789-94.

24 Fraser GM, Grammoustianos K, Reddy J, et al. Long-term immunosuppression without corticosteroids after orthotopic liver transplantation: a positive therapeutic aim. Liver Transplant Surg 1996;2:411-7.

25 Truelove SC, Witts LJ. Cortisone in ulcerative colitis. Final report on a therapeutic trial. BMF 1955;4:1041-5.

26 Befeler AS, Lissoos TW, Schiano TD, et al. Clinical course and management of inflammatory bowel disease after liver transplantation. Transplantation 1998;65:393-6.

27 Zins BJ, Sandborn WJ, Penna CR, et al. Pouchitis disease after orthotopic liver transplantation in patients with primary sclerosing cholangitis and an ileal pouch-anal anastomosis. Am f Gastroenterol 1995;90:2177-81.

28 Trigger DR, Wright R. Immunological aspects of liver disease. In: Millward-Sadler GH, Wright R, Arthur MJP, disease. In: Millward-Sadler GH, Wright R, Arthur MJP,
eds. Wright's liver and biliary disease. Vol I. Cambridge: eds. Wright's liver and
Saunders, 1992:229-44.

29 Lombardo L, Capaldi A, Poccardi G, et al. Peripheral blood CD3 and CD4 T-lymphocyte function correlate with severity of liver cirrhosis. Int f Clin Lab Res 1995;25:153-6.

30 Feagan BG, McDonald JWD, Rochon J, et al. Low-dose cyclosporine for the treat
Med 1994;330:1846-51.

31 Jewell DP, Lennard-Jones JE, and the Cyclosporin Study Group of Great Britain and Ireland. Oral cyclosporin for chronic active Crohn's disease: a multicentre controlled trial. Eur $\mathcal{F}$ Gastroenterol Hepatol 1994;6:499-505.

32 Stange EF, Modigliani R, Pena AS, et al. European trial of cyclosporine in chronic active Crohn's disease: a 12-month study. Gastroenterology 1995;109:774-82.

33 Kornbluth A, Sachar DB. Ulcerative colitis practice guidelines in adults. Am $\mathcal{F}$ Gastroenterol 1997;92:204-11.

34 Riley TR, Schoen RE, Lee RG, et al. A case series of transplant recipients who despite immunosuppression developed inflammatory bowel disease. Am f Gastroenterol 1997; 92:279-82.

35 Das KM, Vecchi M, Sakamaki S. A shared and unique epitope(s) on human colon, skin, and biliary epithelium detected by a monoclonal antibody. Gastroenterology 1990; 98:464-9.

36 Seibold F, Slametschka D, Gregor M, et al. Neutrophil autoantibodies: a genetic marker in primary sclerosing cholangitis and ulcerative colitis. Gastroenterology 1994; 107:532-6.

37 Brandtzaeg P. Autoimmunity and ulcerative colitis: can two enigmas make sense together? Gastroenterology 1996;109: 307-12.

38 Gyde SN, Prior P, Allan RN, et al. Colorectal cancer in ulcerative colitis: a cohort study of primary referrals from three centres. Gut 1988;29:206-17.

39 Lennard-Jones JE, Melville DM, Morson BC, et al. Precancer and cancer in extensive ulcerative colitis: finding among 401 patients over 22 years. Gut 1990;31:800-6.

40 Ekbom A, Helmick C, Zack M, et al. Ulcerative colitis and colorectal cancer: a population based study. $N$ Engl f Med 1990;323:1228-33. 